\title{
BICENTENARIO Y LA PANDEMIA COVID-19: UNA REFLEXIÓN DESDE LA PERSPECTIVA AXIOLÓGICA
}

\author{
BICENTENNIAL AND THE COVID-19 PANDEMIC: A REFLECTION \\ FROM THE AXIOLOGICAL PERSPECTIVE
}

(iD) Percy Díaz Ylaquijo ${ }^{*}$, (D) Gamaniel Romaní Allende ${ }^{1}$, (D) Nelson Paucca Gonzales ${ }^{2}$

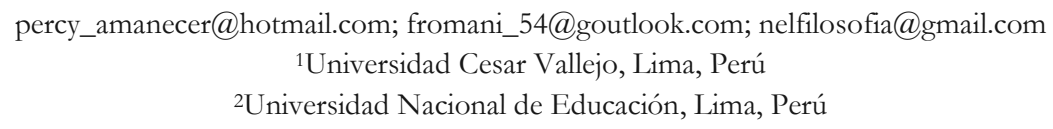

*Correspondencia: Percy Díaz Ylaquijo. Email: percy_amanecer@hotmail.com

Recibido: 01.07.21 | Aprobado: 25.07.21

\section{RESUMEN}

El reconocimiento de la condición humana de la sociedad andina, amazónica y costeña a puertas del Bicentenario es aún un problema fundamental. Por parte de algunas personas que ejercen la política o quizá es pertinente denominarlo como politiquería, esta acción siempre causará desconcierto e inestabilidad en los ciudadanos en nuestro país. Es de notarse con mayor claridad la falta de praxis axiológica por parte de muchos ciudadanos que ejercen cargos políticos, pero también es inconcebible la muestra de ingenuidad de algunos sectores conservadores de nuestro país, bajo el aforismo de ser hombres probos que defienden la democracia. El problema se visibiliza cuando dentro de su discurso estas personas anuncian falacias y clasifican de manera antojadiza a las personas que no comparten sus ideas.

Finalmente, los señores defensores de la democracia terminan queriendo dar órdenes a las instituciones del Estado, vulnerando la autonomía de los poderes. Por otra parte, ad portas del Bicentenario, se enuncia que el Perú viene afrontado el problema de la corrupción y resistiendo el problema de la pandemia COVID-19, por lo que cabe preguntarse ¿Cuánto ha avanzado nuestro país en el aspecto político, económico y social a través de los 200 años?

Palabras clave: Bicentenario, COVID-19, axiología, justicia y derecho.

\section{ABSTRACT}

The recognition of the human condition of the Andean, Amazonian and coastal society on the eve of the Bicentennial is still a fundamental problem, on the part of some people who exercise politics or perhaps it is pertinent to call it politicking, this action will always cause discomfort and instability to the citizens in our country. The lack of axiological praxis on the part of many citizens who hold political office is to be noted more clearly, but it is also inconceivable that some conservative sectors in our country are showing naivety, under the aphorism of being good men who defend democracy. The problem lies when these people within their discourse advertise fallacies and classify in a whimsical way people who do not share their same ideas.

Finally, the defenders of democracy end up wanting to give orders to the institutions of the state, violating the autonomy of the powers of the state. Furthermore, it is stated that Peru, in the name of the Bicentennial, has been facing the problem of corruption and resisting the problem of the COVID-19 pandemic, so it is worth asking: How much progress has our country made in the political, economic and social fields during the 200 years?

Keywords: Bicentennial, COVID-19, axiology, justice and law. 


\section{INTRODUCCIÓN}

La temática Bicentenario y la pandemia COVID-19: una reflexión desde la perspectiva axiológica, tiene sus fundamentos en los hechos prácticos de la vida cotidiana, los cuales se han analizado a partir de un breve esbozo histórico con la finalidad de hacer notar con mayor énfasis la temática del Bicentenario, mientras que la temática de la pandemia tiene sus fundamentos es los estudios realizados y básicamente en los informes de la Organización Mundial de la Salud (OMS). A partir de estos antecedentes hemos analizado las causas y consecuencias que han ido generando, la misma que se ha asumido con responsabilidad de parte de la Instituciones del Estado y los ciudadanos. En los albores del Bicentenario la pandemia ha puesto de manifiesto el problema de la ética y la moral desde el ejercicio práctico de análisis de la falta de praxis de la ética y moral se ha reflexionado básicamente teniendo en cuenta la concepción de Rawls y Hegel. Desde nuestro punto de vista, es una necesidad repensar y rendir cuentas de las condiciones políticas, económicas y sociales que hemos ido adaptando durante los 200 años de nuestra vida republicana.

Para abordar estas temáticas delicadas y controversiales se ha partido de este objetivo; analizar los hechos sociales y las condiciones en las que ha llegado nuestra sociedad al Bicentenario. Esta problemática ha sido elucidada desde la óptica axiológica, priorizando el problema de la justicia y el derecho. Se sabe que, desde que se dio el surgimiento de la sociedad privada, de manera estereotipada se ha clasificado a los ciudadanos de una sociedad en clases sociales, resaltando básicamente dos clases; por un lado, están los llamados de la clase social alta y, por otro, los llamados de la clase social baja. Estas clasificaciones con el trascurrir del tiempo en nuestro país han ido subcategorizándose en clase alta, media, baja y pobres, aunque en estos tiempos clasificar de este modo no tiene mayor sentido. En todo caso surge una primera interrogante; ¿Cuáles serían las condiciones para clasificar de este modo? Además de estas, surgen otras denominaciones como el de ciudadanos de primera clase y segunda clase. Problemáticas de este tipo debe ser analizadas a partir del Bicentenario. En el presente caso, nuestras pretensiones han sido repensar el dilema del desenlace en el año 1821 y las condiciones por las que estamos atravesando a la fecha. En última instancia, sostenemos que lo que no se supera hasta nuestros días, son los complejos que hemos desarrollado durante el proceso histórico, desde los gobernantes y el empresariado. En buena cuenta, parecer ser que no hemos logrado entender la condición humana. Mientras no se logre entender que cada ciudadano cumple una función específica dentro de la sociedad, el intento de la reconciliación queda solo en su versión utópica. En estos momentos hay una polarización dentro de nuestra sociedad bajo las denominaciones de izquierda y derecha, asociándose antojadizamente la primera al comunismo y la segunda a la democracia. Esta falsas y erróneas denominaciones por un sector no intelectual, es decir, por gente dedicado a la politiquería, lo único que harán es mucho daño dentro de la sociedad, por lo que la responsabilidad que nos toca a cada uno de los ciudadanos en todo tiempo es la de sumar, tarea que solo es posible conciliar a partir del reconocimiento de la condición humana entre todos los sectores de nuestro país. En la práctica los ciudadanos de la zona andina, amazónica y costeña hemos sido siempre un complemento, concepción que se pretende 
ocultar en las campañas electorales, pero una vez que estas terminan todo vuelve a su misma condición. En la última elección presidencial se ha notado con claridad el rechazo de los políticos tradicionalistas que solo prometen y luego olvidan lo que dijeron, rechazo que está generando un conflicto social por capricho de un sector político que se hace llamar representantes de la democracia, cuando realmente muchos de estos personajes están atravesando diversos procesos judiciales por el delito de corrupción, tal cual es el caso de la lideresa de Fuerza Popular.

Finalmente, se puede concluir desde la perspectiva axiológica que hacer prevalecer la justicia y los derechos fundamentales en nuestra sociedad aún es utópico. Por lo que es una necesidad elucidar el sentido de la justicia, bajo la consigna de los representes de las instituciones públicas, como entes rectores de la distribución y de velar por el cumplimiento de la justicia y los derechos básicos de todos los ciudadanos de manera equitativa.

\section{EL BICENTENARIO: UNA ETAPA DE CAMBIO}

El Bicentenario se refiere al cumplimiento de los 200 años de vida republicana de nuestro país, a partir de la proclama hecha por José Francisco de San Martín y Matorras, generalmente conocido con el nombre de Don José de San Martín. Este arribó a nuestro país el 8 de septiembre de 1820, acompañado con un promedio de seis mil soldados de nacionalidad argentina y chilena. La mayoría de ellos estuvo conformada por personas del color negro y mulatos que habían ido recobrando su libertad y creían que era justo luchar por una causa legítima llamada libertad.

A partir de 1532 hasta la llegada del libertador, nuestro país estuvo sometido al dominio del yugo español. Es reconocible el trabajo realizado por San Martín y compañía, pero también cabe aclarar que antes de la llegada del personaje, la lucha por la independencia no cesó, es decir, desde el momento que llegaron los invasores, nuestros compatriotas no renunciaron a su libertad. Estas luchas por la independencia, tuvieron mayor auge a inicios de los años 1800, a través de acciones tales como:

[...] la rebelión de Tacna (1811), la de Huánuco (1812) o la revolución del Cusco de 1814. [...] La independencia se juró el 5 de abril de 1819 en Supe, el 28 de noviembre de 1820 en Tarma y el 29 de diciembre, de ese mismo año, en la Intendencia de Trujillo (McEvoy, 2021,2).

Esto indica que al momento en que llegó San Martín y la empresa libertadora, el virrey representante del rey de España en Perú estaba llegando a un final. Con esta afirmación no se pretende desmerecer el trabajo del conjunto de libertadores. Se sabe con claridad que la situación en que se encontraba nuestro país era bastante trágica, por lo que la empresa libertadora tuvo que preparar diversas estrategias además de reunirse con los intelectuales de la época acerca del destino de nuestro país. Una vez logrado cierto consenso con un sector de la población peruana, se procedió a consolidar la independencia del Perú el 28 de julio del año 1821 bajos las frases:

"El Perú es desde este momento libre e independiente por la voluntad general de los pueblos, y por la justicia de su causa que Dios defiende”. Batiendo después el pendón y en el tono de un corazón anegado en el placer puro y celestial que solo 
puede sentir un ser benéfico, repetía muchas veces: "Viva la Patria. Viva la Libertad. Viva la Independencia" (Gaceta del Gobierno de Lima independiente (tomos del I al III, julio 1821-diciembre 1822). Citado en Piccone, 2018, p. 103).

Nuestro propósito de hacer esta referencia es solo para hacer notar a que se refiere o en función a qué se denomina Bicentenario, para el cual ha sido necesario describir estas nociones de hechos históricos a grandes rasgos. En ese sentido, también es necesario hacer notar que con la proclama de la independencia no se logró el objetivo plenamente. Sin embargo, es menester evocar que a partir del 28 de julio de 1821 nuestro país entra a una nueva etapa de proceso transitorio, estando por conmemorarse los 200 años de vida república el 28 de julio de 2021.

En referencia a lo acotado en las líneas precedentes, es una obligación moral hacer un balance acerca de las condiciones en que hemos llegado al bicentenario, qué cambios trascendentales se ha logrado hasta la fecha, y hacia dónde apunta el destino de nuestro país. Cuestiones como estas se elucidan en el presente trabajo desde la perspectiva axiológica resaltando el aspecto de la justicia y los derechos de las personas que se han puesto de manifiesto al acercarnos al Bicentenario. Actualmente nuestro país atraviesa por una situación relativamente similar en los diferentes aspectos, básicamente en el aspecto político. A diferencia de lo que ocurría 200 años atrás, los hechos en nuestros tiempos salen a la luz de manera instantánea. El dominio de la corrupción es predominante por la clase gobernante, la que se obstina en aferrarse al poder con acciones que han demostrado que los derechos de los ciudadanos no tienen importancia alguna, sino lo que prima para ella son más bien sus intereses personales y de clase, tal cual lo muestra el caso de la candidata Keiko Fujimori, lideresa de Fuerza Popular.

El 11 de abril del año en curso se llevaron a cabo las elecciones generales en nuestro país, a las cuales se presentaron 18 candidatos (ONPE, 2021). Debido a la gran cantidad de candidatos, solo pasaron a una segunda vuelta dos candidatos, Keiko Fujimori, candidata por Fuerza Popular y Pedro Castillo, candidato por Perú Libre. Aunque estas elecciones se llevaron a cabo el pasado 6 de junio, han pasado más de 25 días y aun no hay un ganador formalmente proclamado por el Jurado Nacional de Elecciones, debido a que la lideriza de Fuerza Popular y sus aliados han venido haciendo interpelaciones sin tener en cuenta lo que establecen las normas electorales vigentes. En otros términos, los a todas luces perdedores en la contienda electoral se han dedicado a prolongarla ad infinitum. Dentro de las razones axiológicos se hace notar claramente la falta de moral de parte de estas personas y la privación de derechos al bien común, a lo cual se suma la pandemia del COVID-19 que azota a los ciudadanos del país. Estos hechos no parecen ser de interés para estas personas, cuya principal preocupación parece ser más bien ocupar el cargo a toda costa, no importando si los demás padecen de alguna necesidad básica. Con sus acciones dilatorias lo que están logrando es la polarización de los ciudadanos y la inseguridad de parte de los inversionistas extranjeros.

Con estas referencias lo que pretendemos mostrar es que, tras 200 años de vidas republicana pareciera que no hemos avanzado mucho. Existe la polarización en dos o más grupos por capricho de una candidata respaldada por un sector supuestamente pudiente. En buena cuenta se ha reflexionado desde la mirada Rawls, el cual sostiene que las cosas 
son justas siempre que este vele por los interese del bien común. En última instancia cabe sostener que el derecho de la minoría no puede atentar contra el derecho al bien común establecido en la Constitución Política del Perú.

\section{TIEMPOS DE PANDEMIA COVID-19}

La pandémica enfermedad por coronavirus (COVID-19) ha puesto en evidencia la precariedad en la que se encuentra el Estado en pleno siglo XXI En tiempos como hoy observar hechos catastróficos en lo que concierne a la condición humana nos lleva a repensar el papel que cumple es Estado y los diferentes poderes. En principio, la pandemia ha revelado la situación real del sistema, la misma que muestra ser deficiente en lo que concierne a la capacidad de organización, por lo que cabe plantearse lo siguiente: ¿Qué tan eficiente ha estado el sistema de salud? ¿De qué manera ha respondido el Estado a los diferentes sucesos antes, durante y después de la pandemia? Estas interrogantes llevan al hombre de hoy a adoptar una visión holística acerca de la vida y la sociedad. El Estado no ha podido afrontar con eficacia la presente situación, a lo cual se suma la actitud inapropiada de la ciudadanía, por lo que hasta el momento se ha registrado la pérdida de 192163 vidas humanas (OMS, 2021). A pesar de lo duro y dramático de estas cifras, muchas personas no parecen estar dispuestas a asumir responsabilidades frente a la crisis sanitaria sino más bien han mostrado en la mayoría de los casos una actitud de atrevido desafío al contagio y a la muerte bajo el lema de "no tengo qué comer y si no trabajo no como". Es muy comprensible la reacción del hombre frente a las situaciones caóticas como las que nos ha tocado vivir a cada uno de nosotros. Somos tan diversos los seres humanos que en la mayoría de casos han ido mostrando cierta resistencia frente a las medidas de bioseguridad. A pesar de estar a su alcance, se ha optado por la indiferencia e insensibilidad frente a los demás. Estas acciones explicitan el giro radical que los humanos están implantando en la sociedad, perdiendo la praxis de los valores culturales del bien. A los hombres con mala praxis de valores no les quita el sueño la posibilidad de que las autoridades les imponga las medidas de bioseguridad, por lo que su cumplimiento debe ser vigilado, ya que de no ser así van a continuar desafiando el sentido común.

Por otra parte, cabe resaltar que el Estado no ha desarrollado un plan estratégico para enfrentar esta situación crítica y muchos tampoco han tomado conciencia acerca del cuidado que cada uno debe tener. En ese sentido, el problema parece radicar en la falta de toma de conciencia por parte de los ciudadanos frente a la situación caótica por la que estamos atravesando. En caso de no tomar las medidas preventivas de manera individual, el Estado hará poco o nada. Además, es claro que el sistema de saludo ha colapsado, y lo que en muchos años no se había implementado en cuanto a infraestructura y equipos tecnológicos, va a ser imposible de subsanar en unos pocos días.

El nuevo virus SARS-Cov2, ha causado una severa pandemia a nivel mundial, desatando pánico y alarma universal, ha generado el colapso del sistema sanitario en muchas regiones del planeta, por ser muy contagioso, causando miles de muertes especialmente en adultos mayores con comorbilidades como diabetes mellitus o hipertensión arterial (Maguiña, Gastelo y Tequen, 2020, p. 129).

La situación no se ve nada favorable, el nuevo virus que se está produciendo ataca a cualquier persona sin tener en cuenta edad, condición económica o contexto geográfico. 
En sus inicios el virus solo afectó a los adultos mayores; en otros casos, a personas que sufrían de algunos otros males como diabetes o problemas respiratorios, entre otros. Por lo expuesto, consideramos menester una vez más reflexionar sobre el papel de la justicia como un derecho fundamental de las personas. Hay sectores de la clase media y baja que sostienen que la justicia es una utopía. Para responder estas conjeturas, creemos necesario repasar el sentido de lo que es justicia y derecho, para lo cual recurrimos ahora a los aportes de Rawls y Hegel.

\section{LA JUSTICIA DESDE LA CONCEPCIÓN DE JOHN RAWLS}

Rawls es uno de los autores que ha desarrollado de manera holística la noción de justicia. Su obra Teoría de la Justicia, con fundamentos teóricos útiles para elucidar la situación controversial que ocurren en un determinado contexto, bien puede ayudarnos a esclarecer la situación por la que hoy atraviesa nuestro país.

Para un esclarecimiento del concepto justicia, Rawls (2000, p.17) sostiene que "la justicia es la primera virtud de las instituciones sociales, como la verdad lo es de los sistemas de pensamiento". Desde la perspectiva del autor, la justicia es una virtud de las instituciones, esto implica que los representantes de las instituciones públicas y privadas están en la obligación de impartir justicia. Además de velar por el cumplimiento dentro de la sociedad, el cumplimiento de la justicia debe estar rígida dentro de cánones de la Constitución Política del Perú, puesto que esta es la norma suprema que regula los deberes y derechos de los ciudadanos dentro de un determinado contexto. En el presente caso, la carta magna data del año 1993. Sin embargo, se debe tener en cuenta que el hombre es uno de los seres más complejos, por lo que realiza acciones no contempladas dentro de las normas legales respecto a los deberes y derechos. Cuando ocurren estos hechos, muchas veces no sabemos cómo regular estas acciones y recae al libre albedrío de quien imparte justicia - el juez. La sentencia emitida por este último en muchos casos es inapelable, esta emisión bajo la concepción del sentenciado es injusta y se asume que la institución encargada de estas acciones no está cumpliendo con su deber. Desde una concepción empírica, estas acciones ameritan repensar lo que se entiende por justicia en sociedades como la nuestra y de América latina en general. Estos hechos están relacionados básicamente con el cumplimiento de deberes por los ciudadanos: el hombre de hoy ha olvidado su deber y solo reclama derechos. En tiempos de crisis los ciudadanos solo saben pedir y juzgar al Estado, sin tener en cuenta la misión que les corresponde asumir como ciudadanos. Es una necesidad que los ciudadanos tomen conciencia acerca de los hechos críticos y asumir responsabilidades para la construcción de la sociedad. Estamos cerca del Bicentenario y aún seguimos buscando culpables sin asumir nuestra obligación como sujetos esenciales de la sociedad.

\section{EL DERECHO DESDE LA PERSPECTIVA DE HEGEL}

Desde la concepción de Hegel (1968, p. 69). El Derecho, primeramente, es la existencia Inmediata que la libertad se concede, de manera directa [...] La división del Derecho, en Derecho de las personas, de las cosas y Derecho de las acciones, así como las otras múltiples divisiones semejantes, tiene, ante todo, el fin de conducir la multiplicación de la presente materia inorgánica hacia un orden externo. 
Cotidianamente hemos asumido que el derecho es una facultad propia y exclusiva de los seres humanos, es decir, solo los humanos somos poseedores de derechos, olvidando que todos los seres somos dignos de gozar del derecho. En ese sentido, desde la concepción Hegeliana se resalta que el derecho es la libertad con que cuentan los individuos desde el momento de su concepción hasta el último día de su existencia. Esta, a su vez, se considera desde tres perspectivas sumamente relevantes: (1) el derecho de las personas, rubro en el que se consigna lo que les corresponde a las personas, señalándose también que cada individuo es poseedor de deberes. Se tiene claro que el individuo como sujeto de deberes tiene que actuar en función a lo que aspira el bien común; (2) el derecho de las cosas, propuesta que se puede entender fácilmente desde la concepción animista. En nuestro país está concepción está vigente y latente para dos grandes segmentos de la población a los que solemos referirnos como andinos y amazónicos, segmentos étnicos que aún mantienen vivo el pensamiento ancestral según el cual las cosas tienen vida y solo cuidándolas es posible respetar y cuidar lo existente, concepción que bien se podría relacionar con (3) el derecho de las acciones. Si bien es cierto las nociones de Hegel corresponden al campo de la abstracción, son interesantes porque nos llevan a reflexionar acerca del derecho de las cosas, es decir, sobre la vivificación de las cosas a fin de preservar el medio natural; de la misma forma, el derecho de las acciones estaría relacionado con el entorno, cumpliendo el papel vinculante entre el hombre y su medio, lo que conlleva el uso racional de las cosas y la interacción con los animales en lo que respecta a su cuidado desde el accionar de los hombres.

La justicia como imparcialidad permitió evidenciar algunas ideas principales de la teoría de la justicia en sí, por lo que es de suma importancia el entendimiento del papel de la justicia en nuestra sociedad actual. Rawls (2000) sostiene que la justicia es la primera virtud de las instituciones, por ende, se concibe el papel de la justicia como el derecho asegurado, y por esta razón no debe estar sujeta a discusión política ni, tampoco, al cálculo de los intereses sociales. Por otra parte, asumiendo que la praxis de lo justo conduce a los hombres a ser virtuosos, la justicia debe ser garantizada por las instituciones del estado. Además, El derecho y la justicia obedecen a la estructura y orden de una sociedad de tal modo que el proyecto de vida de los individuos está asegurado y difícilmente podrá ser vulnerado. En lo que concierne al objeto de la justicia, sigamos a Rawls:

Para nosotros, el objeto primario de la justicia es la estructura básica de la sociedad o, más exactamente, el modo en que las grandes instituciones sociales distribuyen los derechos y deberes fundamentales y determinan la división de las ventajas provenientes de la cooperación social. Por grandes instituciones se entiende la Constitución Política y las principales disposiciones económicas y sociales (2000, p. 17).

Desde la concepción del Rawls, el objeto de la justicia es considerada como la estructura básica de la sociedad, y dentro de ella están involucrados las grandes instituciones cuya función es la de impartir y vigilar el cumplimiento de los derechos y los deberes fundamentales de los ciudadanos contemplados en la Constitución Política del Perú. La distribución equitativa de la justicia requiere de un estado organizado en donde los funcionarios tienen una noción clara de lo que significa la sociedad en común. En los últimos años se ha notado el desorden que existe entre las instituciones del Estado en su 
afán de disputarse la toma del poder. En estos momentos la lucha entre el poder ejecutivo y el legislativo es incesante, mientras la población ha sido reducida a su mínima expresión bajo el dilema del confinamiento, circunstancia que no ayuda a que en nuestro país se evidencie la aplicación de la justicia. En última instancia, respecto a la principal idea de la teoría de la justicia, el cumplimiento del principio de la teoría dependerá de las personas libres y racionales, de quienes estén motivados en promover la aplicabilidad de la teoría en beneficio de una sociedad y no pensando solo en los intereses de un cierto sector o intereses personales. En cuanto exista una praxis de la teoría y la aplicación equitativa de la justicia se podrá sostener su imparcialidad, de lo contrario se corre el riesgo de contemplarse solo en el enfrascamiento de una sociedad utópica.

Los principios de la justicia permiten entender la aplicación de la justicia por parte de las instituciones del Estado sin vulnerar lo que establece la Constitución Política del Perú. La institución y la justicia formal deben entenderse partiendo de los siguientes:

Hemos visto que estos principios habrán de gobernar la asignación de derechos y deberes en estas instituciones, y que habrán de determinar la correcta distribución de los beneficios y las cargas de la vida social. Los principios de la justicia para las instituciones no deberán confundirse con los principios que se aplican a los individuos y a sus acciones en circunstancias particulares (Rawls, 2000, p. 62).

Respecto al primero, la propuesta enfatiza que nuestra sociedad posee ciertas deficiencias respecto a una estructuración de tipo organizacional, es decir, las instituciones carecen de una continuidad y visión de futuro de parte de los actores responsables que ocupan ciertos cargos en el Estado; respecto al segundo, tanto los representantes del Estado como los ciudadanos desacatan el cumplimiento de las normas: Se ha podido notar que el Estado no tiene una alternativa de solución frente a los diversos problemas que se pueden suscitar, cuestión que se vincula justamente con dos aspectos: la capacidad de gestión y el liderazgo de parte del gobierno. Asimismo, los responsables de velar por el cumplimiento de la justicia y distribuir los beneficios dentro de la sociedad incumplen sus funciones, consecuentemente el pueblo siempre está en la miseria. En última instancia, respecto a la igualdad de oportunidades, se formula la siguiente pregunta: ¿Es posible encontrar igualdad de oportunidades en nuestro país? Aun cuando la pregunta genera una controversia, cabe ensayar la siguiente reflexión: primero, desde la perspectiva de la teoría de la justicia, no es posible. La teoría enfatiza que un Estado debe estar organizado de manera sólida y los funcionarios deben cumplir con la misión encomendada; segundo, nuestro país adolece de líderes políticos con visión de futuro y compromiso con las necesidades del país; tercero, nuestro país es diverso, aspecto que no ha podido ser asimilado por quienes ejercen el poder. Para que la justicia sea imparcial, estos tres elementos planteados deben ser tomado en cuenta con la finalidad de dar alternativas de solución. Dentro de una sociedad como la nuestra, además, quien ejerce el poder debe gozar de libertad y autonomía, a fin de no caer en el condicionamiento de los grandes capitalistas o de su propio interés.

En un contexto en el que se cuestionan las actitudes inmorales de las autoridades, los mismos que han ejercido y ejercen cargos públicos han sido cuestionados por los ciudadanos de todas las esferas, quienes conciben la justicia como una utopía. A fin de 
analizar esta problemática, en primera instancia, es pertinente elucidarla desde la concepción de teóricos como Rawls, Kelsen y Bilbeny. Desde la concepción de Rawls (2006), una sociedad ordenada será capaz de impartir justicia entre los miembros de una sociedad: "[...] una sociedad bien ordenada como una sociedad planeada para incrementar el bien de sus miembros, y eficazmente regida por una concepción pública de la justicia” (p.410). Por ende, en una sociedad ordenada difícilmente podrá existir injusticia entre sus ciudadanos. Por tanto, si la justicia es alcanzable por todos, deja de ser utópica. Por otra parte, Kelsen (1982), refiriéndose al sistema social, sostiene:

[...]. El sistema social puede requerir un determinado comportamiento humano sin enlazar al cumplimiento o incumplimiento de la orden consecuencia alguna. Pero también puede exigir determinada conducta humana y simultáneamente ligar a ese comportamiento la concesión de una ventaja, de un premio; o, a la conducta contraria, una desventaja, una pena (en el sentido más amplio del término).

Desde la perspectiva de Kelsen, dado que el sistema social involucra a todas las personas que integran la sociedad, el cumplimiento de la justicia dependerá del comportamiento que ejercen los ciudadanos. En caso de nuestro país, el problema radica en que las personas que ejercen cargos públicos, y a esto se suma el comportamiento inmoral de los propios ciudadanos, lamentablemente evidencian poca conciencia acerca de la praxis del buen vivir. Finalmente, desde la concepción de Bilbeny (1982), la ética y moral sostenida: "En las lenguas modernas los nombres de Moral y Ética, en su uso filosófico, referirán generalmente lo que es investigación sobre usos y costumbres" (19). La ética como disciplina filosófica presenta ciertas controversias dentro de la historia de la filosofía. Cabe resaltar que el problema es de traducción, ya que el término éthos en griego se traduce como costumbre y, desde el griego, el término éthos se ha traducido al latín mores, que también significa costumbre. En el presente caso, se resalta el término moral como el ejercicio del bien y del mal, el mismo que permite asociar la práctica del bien y del mal de parte de las autoridades que hacen el mal uso de sus funciones, a lo cual los ciudadanos llaman lo injusto; del mismo modo, es también notorio que un buen apreciable número de ciudadanos ejercen malos hábitos apelando a la cultura de la viveza, lo cual no conduce a un accionar de lo bueno.

En referencia a la concepción de Bilbeny (1982) en torno a la ética y la moral, se elucidan la mala praxis de las autoridades en nuestra sociedad, hechos que se han ido agravando con mayor visibilidad a partir de la década de los 90. Con el transcurrir del tiempo, aunque se pensó que esta situación mejoraría, lo que se ha notado es más bien la lenta agonía de un país en caos, básicamente por las malas acciones de las autoridades representativas de nuestra nación, hecho caótico que se ha visibilizado más a partir de la pandemia COVID 19 que sigue azotando al mundo entero. Las autoridades de diferentes países han ido afrontando este desafío con bastante acierto, mientras que en nuestro país han saldo a la luz hechos reprobables como el de la compra irregular de las vacunas y su mal uso por parte de autoridades que están involucrados con las 470 personas que se han vacunado de manera ilegal, encabezados por el ex presidente Martin Vizcarra, los altos funcionarios públicos y en algunos casos los familiares de aquellos. Partiendo de estos hechos cabe plantearse la siguiente pregunta: ¿Qué papel debe cumplir la familia como legitima autoridad? Esta incógnita es posible responderla desde la concepción de Rawls 
(2006); "El niño no tiene sus propias normas críticas, porque no está en condiciones de rechazar preceptos sobre bases racionales. Si quiere y confía en sus padres, tenderá a aceptar sus mandatos" (p.420). En realidad, es una situación compleja entender a los ciudadanos es sumamente difícil. El hombre es un ser inacabado y cambiante, por no decir irracional. Aunque en el caso de los niños son entendibles sus acciones impropias, estas acciones del bien y del mal dependerán de las enseñanzas de los padres de familia. Aquí surge el punto de desigualdad o propiamente llamado la injusticia: mientras que el pueblo educa a sus hijos con buenos modales, las autoridades enseñan los malos hábitos con el ejemplo a sus descendientes. Naturalmente esto es peligroso ya que estas gentes suelen siempre asumir el poder y probablemente la inmoralidad se va asumiendo como parte de la normalidad a pesar de conocer las normas legales. A pesar de estos hechos caóticos de parte de las autoridades, aún debe primar la obediencia y la virtud en los ciudadanos. En realidad, ser hombre virtuoso es una excepción dentro de una sociedad como la nuestra. El hombre debe buscar lo que es lo justo. Desde la óptica de Aristóteles (1985), el hombre virtuoso es aquel que busca el justo medio, es decir, el hombre no se inclina por el exceso ni por el defecto. Estas cuestiones son admisibles por los hombres de toda clase y para lograr el justo medio solo se necesita voluntad. Como colofón de estas reflexiones, cabe sostener que muchos de las autoridades de nuestro país son inmorales, por ende, existe injusticia entre los grupos del poder y por ello el pueblo concibe como la justicia como una utopía.

Habiendo sostenido que la mayoría de las autoridades son inmorales, ya que hacen uso y abuso de su cargo, en lo que sigue se esbozará la moral de los principios. Rawls (2006), haciendo referencia a una sociedad ordenada, había sostenido la posibilidad de una distribución equitativa de la justicia entre los ciudadanos sin restricción alguna; además, en una sociedad ordenada las normas se conciben como justas y, por ende, los ciudadanos tienen interés en participar en asuntos políticos y en ejercer funciones legislativas, judiciales y otros similares. Siguiendo la línea de pensamiento de Rawls, cabe sostener que un hombre prudente tiene sentido de culpa e indignación, y también es evidente que todos los hombres tienen un sentimiento de culpa y está, casi siempre presto a ser subsanado; sin embargo, existen personas que no saben diferenciar entre el bien y el mal, y generalmente se dejan llevar por sus emociones. Tal es el caso de un violador, quien muchas veces siente placer por su acto inmoral. Si aceptamos la premisa de que solo el hombre prudente será capaz de buscar el punto medio para equilibrar el bien y el mal, la pregunta sería, ¿qué es el bien y el mal para las autoridades inmorales? Líneas arriba se esbozó la idea de que el aprendizaje del bien y el mal está relacionado con la formación de la autoridad, en este caso, el padre de familia. Sin embargo, cabe notar que la corrupción se da en las altas esferas y estos hechos son es fiel reflejo de la enseñanza de la familia. Además, al no tener una formación sólida en valores desde su infancia el ciudadano fácilmente será influenciado por los malos hábitos de los miembros de la sociedad. En última instancia, la posibilidad de la praxis de una moral de manera correcta aún es posible dentro de una sociedad en crisis, siempre existe la posibilidad de obrar por el bien, no por la imposición, sino porque los hombres se rigen en función a sus obligaciones, las mismas que son reguladas a través de las normas vigentes como principio categórico de la moral. 
Apelando a una sociedad ordenada, un sistema social sensible y a una legitimidad moral de las autoridades, se sostiene que los principios de la base de la igualdad constituyen una alternativa que concilia a las autoridades y los ciudadanos. En ese sentido, la administración de las instituciones cumple una función imprescindible dentro de una sociedad ordenada. Los representantes de las instituciones son personas morales con derecho a una justicia igual, en tanto, a esta última se asume que son personas probas en la materia y están en condiciones de distribuir la equidad de la justicia entre todos los ciudadanos. Además, estas se distinguen en función a las siguientes características: primero, son capaces de tener un sentido del bien y, segundo, son capaces de un sentido de justicia. Estas características aseguran a la ciudadanía contar con una justicia igualitaria. Por otra parte, la aplicabilidad de la igualdad es potestad de las autoridades con principios ético-morales. En caso de que se infrinja esta base de igualdad, se estaría llevando al punto original que se había planteado: que la justicia es una utopía. En última instancia, la base de la igualdad dependerá también de las buenas conductas de los ciudadanos. No se puede obtener justicia sin obrar por la praxis del bien. Los ciudadanos están obligados a cumplir y hacer cumplir las normas vigentes como un derecho y una obligación fundamental del hombre. Además, a esta se tiene que sumar la fuerza de voluntad de cada persona prudente desde su posición original.

\section{CONCLUSIONES}

Bicentenario refiere al cumplimiento de 200 años de la independencia del Perú, proclamado por el general José Francisco de San Martín y Matorras en la ciudad de Lima el 28 de julio de 1821, fecha en la cual se emitió el mensaje de libertad a la ciudadanía en general, promesa supuestamente válida a partir de este hecho hasta nuestros días. De manera simbólica los presidentes de la república siempre suelen dar un mensaje esperanzador a los ciudadanos cada 28 de julio.

La pandemia COVID-19, enfermedad por coronavirus que apareció en los últimos meses del año 2019, es uno de los males que azotó y sigue azotando hasta nuestros días a los ciudadanos de nuestro país, lo cual hasta el momento ha generado una perdida 192163 vidas humanas, tal como revelan fuentes de la OMS.

Respecto a la justicia se concluye: primero, una sociedad ordenada con autoridades probas, con principios éticos, garantiza la distribución equitativa de la justicia entre los ciudadanos de una sociedad; segundo, el desarrollo pleno de la ética y la moral como costumbre dentro de una sociedad depende de una enseñanza activa de parte de las autoridades y padres de familia y ellos serán todos ellos los responsables del cumplimiento de lo que es lo justo en base a las normas morales; tercero, en una sociedad ordenada existe la posibilidad de la distribución equitativa de justicia lo que, además, genera en el ciudadano confianza en las instituciones públicas y en quienes administran y asumen funciones políticas, legislativas y judiciales; cuarto, la base de la igualdad radica en la voluntad de las autoridades y personas prudentes, quienes se caracterizan por la búsqueda del justo medio entre el exceso y lo defectuoso. Con la praxis del justo medio se descarta la posibilidad de una justicia utópica por parte de los ciudadanos de la clase medio y baja de la sociedad; quinto, la justicia es un elemento inherente al hombre, la misma que debe ser distribuida de manera equitativa por los representantes de las instituciones del estado, 
y el derecho es propio de cada individuo; sexto, la justicia es imparcial cuando un Estado tiene una base estructurada y una organización sólida, la cual imparte justicia teniendo en cuenta las normas contempladas en la Constitución Política del Perú y, séptimo, las instituciones del Estado muestran cierta deficiencia en la distribución de justicia como derecho y deber de los ciudadanos, por lo que se genera una desigualdad social.

En última instancia cabe esbozar que la teoría de la justicia propuesto por Rawls nos ha permitido analizar la situación actual en la que se encuentra nuestro país En ese sentido, nuestra misión es idear como afrontar la situación crítica desde nuestra condición de ciudadanos. A modo de reflexión, cabe concluir que la justicia es un derecho fundamental de los hombres y, por ende, es responsabilidad de todos construir un país sólido lejos de un sueño utópico e injusto.

\section{REFERENCIAS BIBLIOGRÁFICAS}

Aristóteles. (1985). Ética Nicomáquea - Ética Eudemia (6ta reimpresión). Gredos.

Bilbeny, N. (2012). Ética. file:///C:/Users/user/Downloads/Bilbeny_Etica_pdf.pdf

Evoy, C. CM. (2021). Perú y su largo camino a la libertad. https://www.bcrp.gob.pe/ docs/Billetes-Monedas/Monedas-de-Coleccion/bicentenario-2021/bicentenariointroduccion.pdf

OMS. (2021). World Health Organization. https://www.who.int/countries/per/.

ONPE. (20021). Información al: 17/03/2021 11:36:05. https://www.embaperu.ch/site/ wp-content/uploads/2021/03/FDIF_P_PRESIDENCIAL_V001_A3.pdf

Piccone Camere, C. (2018). "Por la justicia de su causa que Dios defiende": José de San Martín y la liturgia republicana. file:///C:/Users/user/Downloads/Dialnet-PorLaJusticiaDeSuCausaQueDiosDefiende-7022663\%20(1).pdf

Kelsen, H. (1982). Teoría del derecho puro. file://C:/Users/user/Downloads/Teor\% C3\%ADa\%20pura\%20del\%20Derecho\%20-\%20Kelsen.pdf

Rawls, J. (2006). Teoría de Justicia (2da reimpresión). https:/ / etikhe.files.wordpress.com/ 2013/08/john_rawls_-_teoria_de_la_justicia.pdf

Castaño, A. (2013). El concepto de justicia y su fundamento. Un análisis de los consensos en J. Rawls desde la perspectiva del nuevo derecho natural en Carlos Massini. http://www.scielo.org.co/pdf/ccso/v13n24/v13n24a05.pdf

Hegel, G. F. (1968). Filosofía del derecho. http://upcndigital.org/ ciper/biblioteca/ Filosofia $\% 20$ moderna/Hegel $\% 20-\% 20$ Filoso

fia $\% 20 \mathrm{del} \% 20$ Derecho.pdf

Hernández, J. R. (2015). La justicia social desde un nuevo enfoque de la justicia. análisis del mandato de la organización internacional del trabajo conforme al concepto moderno de la justicia. http://www.scielo.org.mx/pdf/rlds/n21/1870-4670rlds21-00085.pdf. 
Maguiña, C., Gastelo, R. y Tequen, A. (2020). El nuevo Coronavirus y la pandemia del Covid-19. http://www.scielo.org.pe/pdf/rmh/v31n2/1729-214X-rmh-31-02-125. pdf

Rawls, J. (2000). Teoría de Justicia (2da reimpresión). Fondo Cultura Académica.

\section{CITAR COMO:}

Díaz Ylaquijo, P., Paucca Gonzales, N., \& Romaní Allende, F. G. (2021). Bicentenario y la pandemia COVID-19: una reflexión desde la perspectiva axiológica. Puriq, 3(3), 327-339. https://doi.org/10.37073/puriq.3.3.209 